\title{
Recognition of musculoskeletal injuries among endoscopists should gain traction
}

\section{다 (1) $\odot$}

\author{
Author \\ Edward Villa \\ Institution \\ John H. Stroger Hospital of Cook County - \\ Gastroenterology and Hepatology, Chicago, Illinois, \\ United States \\ Bibliography \\ Endoscopy International Open 2020; 08: E1840-E1841 \\ DOI 10.1055/a-1265-6763 \\ ISSN 2364-3722
}

\begin{abstract}
(c) 2020. The Author(s).
This is an open access article published by Thieme under the terms of the Creative Commons Attribution-NonDerivative-NonCommercial License, permitting copying and reproduction so long as the original work is given appropriate credit. Contents may not be used for commecial purposes, or adapted, remixed, transformed or built upon. (https://creativecommons.org/licenses/by-nc-nd/4.0/)
\end{abstract}

Corresponding author

Edward Villa, John H. Stroger Hospital of Cook County, Gastroenterology and Hepatology, 1900 W Polk St 14th Floor, Chicago Illinois 60612-3785, United States

Phone: +1-847-668-3875

eespee88@gmail.com
Endoscopic procedures are, at their core, techniques that supplement clinical evaluations of patients for a variety of gastrointestinal diseases and radiographic findings. With continued evolution of technologies, devices, and innovations, endoscopy has also become a tool with which endoluminal and transluminal interventions are now routinely performed. This has exponentially expanded the nonsurgical approaches to the management of many diseases, including some intraluminal cancers. Third space endoscopy (TSE) and related procedures are established and evidence-supported techniques offering management of diseases previously relegated to operative approaches. However, while the number of third space endoscopists is increasing - particularly in the West where fewer of these techniques are performed as compared to our Eastern colleagues these techniques can be technically challenging, involving longer procedure times and fine, precise movements that may require awkward positioning for longer durations of time.

This study entitled "High prevalence of musculoskeletal symptoms and injuries in third space endoscopists: an international multicenter survey" by Drs. Han, Hammad, and Wagh is an excellent survey-based study that assesses musculoskeletal injuries (MSI) among a subpopulation of endoscopists that perform TSE and highlights yet another arena within endoscopy that exposes even the most skilled to potentially chronic, debilitating injury.

Endoscopic ergonomic studies have been published in greater numbers over the latter half of the past decade and the field is gaining significant traction. While research so far has been mostly limited to survey-based studies involving upper endos- copists and colonoscopists, recognition of musculoskeletal injuries offers insight into populations and potential future interventions that may be necessary to improve the longevity and health of endoscopists. After all, $39 \%$ to $89 \%$ of surveyed endoscopists report pain and/or injuries related to general endoscopic procedures, an alarming number that is reproducible across multiple studies and different endoscopist demographics [1]. Another cause for alarm is that higher rates of endoscopy-related MSI are associated with high procedure volumes and total number of years performing endoscopy with some studies demonstrating significant debilitation - to the point of requiring surgical management in up to $13 \%$ - and even resulting in early retirement in a minority of endoscopists [2-4].

While experience portends higher risks of MSI and their related complications, the risk of MSI begins in the earliest years of endoscopic practice with a reported $20 \%$ to $47 \%$ of gastroenterology fellows reporting endoscopy-related MSI in two United States survey-based studies with the majority (85\%) reporting injuries during their first year of training $[5,6]$.

As such, MSI related to endoscopy becomes a significant issue that warrants further attention and recognition, especially with the ever-increasing demand on all endoscopists - not just those performing general procedures - that is only set to worsen in the peri-/post-COVID world. The study by Han and colleagues offers rather novel insights into MSI among those performing TSE, and no study to my knowledge has researched this subpopulation of endoscopists. MSI among other therapeutic endoscopists have been studied, mostly in ERCP - with 
data revealing that $44 \%$ to $50 \%$ of those performing endoscopic retrograde cholangiopancreatography (ERCP) reported MSI attributed to endoscopic practices $[4,7]$.

In the study by Han et al, of the 45 international respondents from 10 countries, $69 \%$ reported MSI with $49 \%$ of respondents reporting that these injuries were related to TSE. Interestingly, roughly half of respondents reported more musculoskeletal symptoms and injuries related to TSE as compared with ERCP or endoscopic ultrasound. While only a minority of TSE endoscopists missed work (2.2\%), reduced their clinical/procedural schedules $(6.7 \%)$, required temporary disability $(2.2 \%)$, or required surgery for MSI (2.2\%), the reality is that these endoscopists are performing technically challenging, highly skilled procedures that require the highest degree of precision and accuracy, lest a potentially life-threatening complication occur.

The authors delve into the possible mechanistic and technical causes of MSI particular to TSE. However, it is interesting to see that on univariate analyses, no factors investigated in the survey yielded statistically higher impact on MSI, including number of endoscopies performed, which has been statistically significantly associated with development of MSI across several published studies. This suggests that a lower number of cases of TSE can result in MSI or that the low number of cases/respondents may not have had enough statistical power to tease out statistically significant differences. My opinion is that the former is the most likely explanation, given that TSE involves technically challenging, lengthy, high-impact, highly repetitive procedures that likely affect endoscopists at lower procedure volumes than other procedures. Without losing sight of limitations inherent to survey-based studies, it is still important to contextualize the data with what information is known about endoscopic ergonomics. Studies have demonstrated that physical mechanics of endoscopy - namely, overuse injuries resulting from repetitive stress and cumulative trauma, specifically with repetitive microtraumatic maneuvers resulting in collagen and connective tissue weakness and damage - are strong risk factors for acute and chronic injuries. In one study assessing pinch forces of three experienced colonoscopists (with three colonoscopies performed by each endoscopist), right and left forearm activity was measured objectively using surface electromyography and found that mean peak pinch forces of the right thumb and forearm-muscle activities of the left abductor pollicus longus and bilateral extrensor carpal radialis significantly exceeded objectively determined thresholds shown to be associated with increased risk of MSI of the thumb and wrist [8]. What is important to note is that the average procedure time in this study was roughly 20 minutes, far lower than the typical TSE procedure. Thus, when performing TSE, there is likely more muscular and joint strain with similar extremes of range of motion over longer periods of time with fewer breaks, all of which are likely to result in shorter onset to MSI.

The American Society of Gastrointestinal Endoscopy published guidelines in 2010 and briefly delved into the prevalence and pathophysiology as well as basic suggestions for minimizing postural and maneuver-related strain as well as for basic room design to improve the endoscopist-endoscope interaction [9]. However, this knowledge has not fully permeated into practice, as evidenced by an overall lack of ergonomics education (only $28 \%$ to $36 \%$ of gastroenterology fellows received any perceived formal ergonomics training during fellowship) and overall desire by $67 \%$ to $81 \%$ of endoscopists to receive formal ergonomics training [4-6].

Thus, this study of endoscopists performing TSE is an especially important contribution towards recognizing the continued breadth of MSI among endoscopists as well as identifying areas in which further studies and interventions are needed to assess the factors, practices, or technologies that can reduce the impact on endoscopists and lead to longer, healthier practice. After all, the time is now to increase recognition of ergonomic principles and to spark more investigation and innovation that are paramount to the continued health of all of our endoscopists worldwide.

\section{Acknowledgements}

Dr. Villa thanks Dr. Ponchon for the invitation to write this editorial.

\section{Competing interests}

Dr. Villa is a consultant for Olympus Corporation of America and Medtronic plc.

\section{References}

[1] Yung DE, Banfi T, Ciuti G et al. Musculoskeletal injuries in gastrointestinal endoscopists: A systematic review. Expert Rev Gastroenterol Hepatol 2017; 11: 939-947

[2] Ridtitid W, Coté G, Leung W et al. Prevalence and risk factors for musculoskeletal injuries related to endoscopy. Gastrointest Endosc 2015; 81: 294-302

[3] Morais R, Vilas-Boas F, Pereira P et al. Prevalence, risk factors and global impact of musculoskeletal injuries among endoscopists: A nationwide European study. Endosc Int Open 2020; 8: E470-E480

[4] Campbell EV, Muniraj T, Aslanian H. Musculoskeletal pain syndromes and injuries among endoscopists who perform ERCP. Dig Dis Sci 2020: doi:10.1007/s10620-020-06163-z [Published online ahead of print March 6, 2020]

[5] Villa E, Attar B, Trick W. Endoscopy-related musculoskeletal injuries in gastroenterology fellows. Endosc Int Open 2019; 07: E808-E812

[6] Austin K, Shoecnberger $\mathrm{H}$, Sesto $\mathrm{M}$ et al. Musculoskeletal injuries are commonly reported among gastroenterology trainees: Results of a national survey. Dig Dis Sci 2019; 64: 1439-1447

[7] O'Sullivan S, Bridge G, Ponich T. Musculoskeletal injuries among ERCP endoscopists in Canada. Can J Gastroenterol 2002; 16: 369-374

[8] Shergill A, Asundi K, Barr A et al. Pinch force and forearm-muscle load during routine colonoscopy: A pilot study. Gastrointest Endosc 2009; 69: 142-146

[9] Pedrosa MC, Farraye FA, Shergill AK et al. Minimizing occupational hazards in endoscopy: Personal protective equipment, radiation safety, and ergonomics. Gastrointest Endosc 2010; 72: 227-235 